Article

\title{
Development of Liposomal Vesicles for Osimertinib Delivery to EGFR Mutation-Positive Lung Cancer Cells
}

\author{
Paulina Skupin-Mrugalska ${ }^{1, *(1)}$ and Tamara Minko ${ }^{2,3,4}$ \\ 1 Department of Inorganic \& Analytical Chemistry, Poznan University of Medical Sciences, Grunwaldzka 6, \\ 60-780 Poznan, Poland \\ 2 Department of Pharmaceutics, Ernest Mario School of Pharmacy, Rutgers: The State University of \\ New Jersey, 160 Frelinghuysen Road, Piscataway, NJ 08854, USA; minko@pharmacy.rutgers.edu \\ 3 Rutgers Cancer Institute, Rutgers, the State University of New Jersey, 195 Little Albany Street, \\ New Brunswick, NJ 08903, USA \\ 4 Environmental and Occupational Health Science Institute, Rutgers, the State University of New Jersey, \\ 170 Frelinghuysen Rd., Piscataway, NJ 08854, USA \\ * Correspondence: psmrugalska@ump.edu.pl; Tel.: +48-61-854-6699
}

Received: 31 August 2020; Accepted: 28 September 2020; Published: 30 September 2020

check for updates

\begin{abstract}
Osimertinib (OSI, AZD9291), is a third-generation, irreversible tyrosine kinase inhibitor (TKI) of the epidermal growth factor receptor (EGFR) that selectively inhibits both EGFR-TKI-sensitizing and EGFR T790M resistance mutations. OSI has been approved as a first-line treatment of EGFR-mutant lung cancer and for metastatic EGFR T790M-mutant non-small cell lung cancer. Liposome-based delivery of OSI can provide a new formulation of the drug that can be administered via alternative delivery routes (intravenous, inhalation). In this manuscript, we report for the first time development and characterization of liposomal OSI formulations with diameters of ca. $115 \mathrm{~nm}$. Vesicles were composed of phosphatidylcholines with various saturation and carbon chain lengths, cholesterol and pegylated phosphoethanolamine. Liposomes were loaded with OSI passively, resulting in a drug being dissolved in the phospholipid matrix or actively via remote-loading leading to the formation of OSI precipitate in the liposomal core. Remotely loaded liposomes were characterized by nearly 100\% entrapment efficacy and represent a depot of OSI. Passively-loaded vesicles released OSI following the Peppas-Sahlin model, in a mechanism combining drug diffusion and liposome relaxation. OSI-loaded liposomes composed of $\mathrm{L}-\alpha$-phosphatidylcholine (egg-PC) demonstrated a higher toxicity in non-small lung cancer cells with EGFR T790M resistance mutation (H-1975) when compared with free OSI. Developed OSI formulations did not show antiproliferative activity in vitro in healthy lung epithelial cells (MRC-5) without the EGFR mutation.
\end{abstract}

Keywords: liposomes; drug delivery; tyrosine kinase inhibitors; osimertinib; non-small cell lung cancer; EGFR resistance mutations

\section{Introduction}

For several decades, lung cancer has been the most common cancer worldwide and has been accounted for the most common cause of cancer-related deaths [1,2]. Among all types of lung cancer, non-small cell lung cancer (NSCLC) represents approximately $85 \%$ of lung cancer cases with a lower than 15\% 5-year survival [1,3]. Genetic and molecular profiling of NSCLC has led to the discovery of molecular alterations that drive tumor initiation and progression [4]. The above findings have revolutionized treatment management in NSCLC and have helped to improve treatment outcomes and quality of life compared to traditional chemotherapy [5]. In NSCLC, several targetable significant 
pathways have been identified, including EGFR, PI3K/AKT/mTOR, RAS-MAPK, and NTRK/ROS1 pathways [5,6]. EGFR mutations were the first molecular alterations in NSCLC, discovered in 2004 [7], and they occur in 10-28\% of NSCLC patients [8]. In response to the discoveries at a molecular level, drugs targeting the EGFR pathway, tyrosine kinase inhibitors (TKIs) have been developed and shown clinical benefits. First-generation (gefitinib and erlotinib) and second-generation (afatinib) TKIs demonstrated superior progression-free survival, objective response rate, and quality of life compared to standard chemotherapy in patients whose tumors harbored canonical activating EGFR mutations [9-11]. Unfortunately, more than $60 \%$ of patients develop resistance to first- or second-generation TKIs. The common mechanism of acquired resistance to EGFR TKIs is the EGFR T790M mutation [12]. Third-generation inhibitors were created to target the T790M mutations while maintaining activity against the original exon19del and L858R mutations [6].

Osimertinib, (OSI, AZD9291) is a third-generation, irreversible TKI of the epidermal growth factor receptor (EGFR-TKI) that selectively inhibits both EGFR-TKI-sensitizing and EGFR T790M resistance mutations [13]. OSI initially gained FDA approval for patients with metastatic EGFR T790M-mutant NSCLC that had progressed on first- or second-generation EGFR TKIs and has subsequently achieved approval as a first-line treatment of EGFR-mutant lung cancer $[6,13,14]$. OSI is administered orally in the form of film-coated tablets (TAGRISSO ${ }^{\circledR}$ ) containing OSI as mesylate. The absolute bioavailability of OSI was determined as $70 \%$ [15].

Several drug delivery strategies have been previously proposed to enhance the safety and efficacy of TKI-mediated therapy in lung cancer [16-21]. Liposomes are predominant nanocarriers among these delivery systems that have been developed for TKIs delivery. The high interest in liposomes as a TKIs delivery strategy results from its biocompatibility, high encapsulation of lipophilic drugs with the ability to load hydrophilic cargo and surface modifications, e.g., with PEG molecules and targeting moieties [22]. Liposomes are widely accepted as a drug delivery system by regulatory agencies and used as delivery agents in many approved medicinal products [23].

OSI has an acceptable bioavailability after oral administration. However, it has a high in vitro plasma protein binding of $94.7 \%$. OSI has been demonstrated to bind covalently to rat and human plasma proteins, human serum albumin and rat and human hepatocytes [15]. The high affinity for endogenous proteins may raise the risk of adverse drug reactions and decrease the safety profile of the drug [21]. Therefore, we hypothesized that a drug delivery approach combined with local pulmonary delivery could be an attractive alternative to improve the efficacy and safety of lung cancer TKI-based targeted therapy [24,25]. Liposome encapsulation can result in increased accumulation of the drug in the tumor due to the enhanced permeability and retention (EPR) effect [26], leading to more selective deposition of EGFR inhibitor and reduced impacts on critical healthy tissues. Liposome-based delivery of OSI can provide a new formulation of the drug that can be administered by different routes (intravenous, inhalation), especially in patients who cannot take medicines orally and with advanced NSCLC. Such delivery can potentially enhance the efficacy of the treatment and decrease toxicity of drug(s) [24,27-29]. In patients with EGFR mutation-positive advanced NSCLC, there is an unmet need for EGFR-TKIs with improved central nervous system (CNS) penetration and activity against CNS metastases, either at initial diagnosis or time of progression [30]. OSI was shown to have a good brain exposure in human subjects [31] and to be active against CNS brain metastases or leptomeningeal disease, regardless of T790M status [30,32,33]. Patients with brain metastasis may benefit from treatment with liposome-based OSI delivery due to favorable blood-to-brain penetration of the drug and additionally by brain targeting route of administration.

This work was aimed at developing liposomal formulations of OSI and a method of its preparation. Prepared liposomes were evaluated in terms of size, loading efficacy, stability, and release profile. Finally, cytotoxicity in NSCLC: A549 with wild-type EGFR gene, PC-9 with a deletion in exon 19 of the EGFR gene, H-1975 bearing mutations T790M and L858R in the EGFR gene, and human lung fibroblasts, MRC-5, was determined. 


\section{Materials and Methods}

\subsection{Materials}

Osimertinib (OSI) was purchased from SelleckChem (Selleck Chemicals LLC, Houston, TX, USA), thiazolyl blue tetrazolium bromide (MTT) from Sigma Aldrich (Merck KgA, Darmstadt, Germany). L- $\alpha$-Phosphatidylcholine 95\% (Egg-PC), 1,2-dipalmitoyl-sn-glycero-3-phosphocholine (DPPC), 1,2-distearoyl-sn-glycero-3-phosphocholine (DSPC), 1,2-distearoyl-sn-glycero-3-phosphorethanol-amine-N-[methoxy(polyethyleneglycol)-2000] sodium salt (PEG2000-DSPE), and cholesterol (chol; ovine wool, >98\%), were purchased from Avanti Polar Lipids (Alabaster, Al, USA).

\subsection{Methods}

\subsubsection{Preparation of Liposomes}

OSI-loaded liposomes and corresponding non-loaded formulations, presented in Table 1, were prepared by thin lipid hydration with drug-loaded passively during hydration or by an ammonium sulfate gradient-assisted loading.

Table 1. Characteristics of 12 types of liposomes used in this study, which differ from each other in lipid composition and method used for drug loading.

\begin{tabular}{|c|c|c|c|c|c|}
\hline Formulation Liposome Components & $\begin{array}{c}\text { Initial } \\
\text { Molar Ratio }\end{array}$ & Size (nm) & PDI & $\begin{array}{l}\text { Zeta Potential } \\
(\mathrm{mV})\end{array}$ & EE (\%) \\
\hline \multicolumn{6}{|l|}{ Thin Lipid Hydration-Passive Loading } \\
\hline 1-NL $\quad$ Egg-PC/chol/PEG2000-DSPE & $55 / 40 / 5$ & $108.7 \pm 1.3$ & 0.101 & $-10.9 \pm 0.3$ & \\
\hline 1-OSI Egg-PC/chol/PEG2000-DSPE/OSI & $55 / 40 / 5 / 7$ & $114.8 \pm 0.8$ & 0.043 & $-11.4 \pm 0.8$ & $81.5 \pm 6.6$ \\
\hline 2-NL DPPC/chol/PEG2000-DSPE & $55 / 40 / 5$ & $122.0 \pm 1.0$ & 0.036 & $-11.5 \pm 0.0$ & \\
\hline 2-OSI DPPC/chol/PEG2000-DSPE/OSI & $55 / 40 / 5 / 7$ & $119.8 \pm 1.4$ & 0.047 & $-10.3 \pm 0.7$ & $54.2 \pm 10.8$ \\
\hline 3-NL $\quad$ DSPC/chol/PEG2000-DSPE & $55 / 40 / 5$ & $124.4 \pm 2.0$ & 0.049 & $-11.6 \pm 1.4$ & \\
\hline 3-OSI DSPC/chol/PEG2000-DSPE/OSI & $55 / 40 / 5 / 7$ & $125.7 \pm 0.6$ & 0.016 & $-10.4 \pm 0.5$ & $48.6 \pm 7.6$ \\
\hline \multicolumn{6}{|c|}{ Thin Lipid Hydration-Ammonium Sulfate Gradient-Assisted Loading } \\
\hline 4-NL Egg-PC/chol/PEG2000-DSPE & $55 / 40 / 5$ & $110.9 \pm 1.0$ & 0.042 & $-10.3 \pm 0.2$ & \\
\hline 4-OSI Egg-PC/chol/PEG2000-DSPE/OSI & $55 / 40 / 5 / 7$ & $109.6 \pm 0.1$ & 0.051 & $-10.2 \pm 0.9$ & $97.2 \pm 0.7$ \\
\hline 5-NL DPPC/chol/PEG2000-DSPE & $55 / 40 / 5$ & $124.0 \pm 0.6$ & 0.030 & $-10.2 \pm 0.9$ & \\
\hline 5-OSI DPPC/chol/PEG2000-DSPE/OSI & $55 / 40 / 5 / 7$ & $119.1 \pm 1.4$ & 0.047 & $-11.9 \pm 1.5$ & $92.6 \pm 3.6$ \\
\hline DSPC/chol/PEG2000-DSPE & $55 / 40 / 5$ & $125.5 \pm 0.6$ & 0.097 & $-11.5 \pm 1.1$ & \\
\hline 6-OSI DSPC/chol/PEG2000-DSPE/OSI & $55 / 40 / 5 / 7$ & $122.7 \pm 1.0$ & 0.025 & $-11.3 \pm 1.3$ & $94.2 \pm 5.6$ \\
\hline
\end{tabular}

Mixtures of egg-PC (or DPPC or DSPC), cholesterol, and PEG2000-DSPE at molar ratio 55/40/5 were prepared and dissolved in chloroform. For liposomes prepared by thin lipid hydration, OSI at a lipid to drug weight ratio of ca. 20/1 were added to the lipids mixture. Subsequently, the organic solvent was evaporated at $40{ }^{\circ} \mathrm{C}$ to form a thin film which was rehydrated with $10 \mathrm{mM}$ PBS, pH 7.4 (thin lipid hydration) or $250 \mathrm{mM}$ ammonium sulfate (remote loading). In all cases, the hydration step was carried out at temperatures above the gel to liquid crystalline phase transition (Tm) of the phospholipids (at $40^{\circ} \mathrm{C}$ for egg-PC, at $50{ }^{\circ} \mathrm{C}$ for DPPC and $60{ }^{\circ} \mathrm{C}$ for DSPC). Liposomes were extruded gradually using polycarbonate membranes $200 \mathrm{~nm}$ ( 5 times) and $100 \mathrm{~nm}$ (6 times) at room temperature using an extruder device from Northern Lipids Inc. (Vancouver, BC, Canada).

To obtain ammonium sulfate gradient, four consecutive dialysis exchanges, by using Spectra-Por ${ }^{\circledR}$ Float-A-Lyzer ${ }^{\circledR}$, with a molecular weight cut-off (MWCO) of 8-10 kDa (Spectrum Laboratories, Inc., Piscataway, NJ, USA), against 10\% sucrose were used. An ethanol solution of OSI was added to the liposome dispersion after the creation of an ammonium sulfate gradient, during vigorous shaking on an orbital incubation shaker GYROMAXTM 703 (Amerex Instruments Inc., Concord, CA, USA) at 
$250 \mathrm{rpm}$ for $1 \mathrm{~h}$. The loading was performed at temperatures above the $\mathrm{T}_{\mathrm{m}}$ of egg-PC $\left(45^{\circ} \mathrm{C}\right), \mathrm{DPPC}$ $\left(55^{\circ} \mathrm{C}\right)$, DSPC $\left(65^{\circ} \mathrm{C}\right)$.

Non-entrapped OSI was removed by three consecutive dialysis exchanges: against $10 \mathrm{mM}$ PBS, $\mathrm{pH} 7.4$ for liposomes prepared by thin lipid hydration, or 10\% sucrose (1 step), followed by $10 \mathrm{mM}$ PBS, pH 7.4 (2 steps) in case of vesicles loaded with OSI via ammonium sulfate gradient. Subsequently, liposomes were diluted ten times in acetonitrile, and OSI was determined spectrophotometrically by reading absorbance at $308 \mathrm{~nm}$. Encapsulation efficacy (EE, \%) was calculated according to Equation (1):

$$
\mathrm{EE}(\%)=\left(C_{\mathrm{M}} / C_{\mathrm{i}}\right) \times 100
$$

where $C_{\mathrm{M}}$ is the concentration of OSI loaded into liposomes, determined spectrophotometrically, $C_{\mathrm{i}}$ is the maximum concentration of OSI added during liposome preparation.

\subsubsection{Dynamic Light Scattering (DLS)}

The mean size and zeta potential of liposomes were determined by DLS (Malvern Zetasizer Nano ZS; Malvern Instruments Ltd., Malvern, UK). Results were obtained in the backscattering mode at a temperature of $25^{\circ} \mathrm{C}$. Each sample was measured multiple times in a consecutive manner, where each analysis consisted of three measurements from which the average size and the polydispersity index (PDI) was calculated.

\subsubsection{Stability of Liposomes}

For the long-term stability, liposomes were stored in PBS at $4{ }^{\circ} \mathrm{C}$, and particle size and PDI were evaluated at days $0,60,90$.

\subsubsection{In Vitro Release of OSI from Liposomes}

In vitro release of OSI from liposomes was performed by the dialysis method in both neutral (pH 7.4) and acidic (pH 6.1) conditions. $10 \mathrm{mM}$ PBS was used as a release medium. $1 \mathrm{~mL}$ of liposomal OSI formulations were added to dialysis bags ( $8 \mathrm{kDa}$ MWCO, Spectra/Por, Spectrum Laboratories, Inc., Piscataway, NJ, USA) and immersed into $40 \mathrm{~mL}$ of release medium $(n=2)$ in $50 \mathrm{~mL}$ tubes. The tubes were protected from light and shaken at $150 \mathrm{rpm}$ and $37^{\circ} \mathrm{C}$ using an orbital incubation shaker GYROMAXTM 703 (Amerex Instruments Inc., Concord, CA, USA). $0.5 \mathrm{~mL}$ samples were withdrawn from the release medium and replenished with $0.1 \%$ formic acid in $\mathrm{ACN}$ at the predetermined time points. Samples were analyzed by high-performance liquid chromatography (HPLC) using an XTerra C18 column, $125 \AA, 5 \mu \mathrm{m}, 4.6 \mathrm{~mm} \times 150 \mathrm{~mm}$, (Waters Corporation, Milford, MA, USA) operated at room temperature. The mobile phase consisted of $0.1 \%$ formic acid in water/acetonitrile $40: 60$ ( $v: v)$, the flow rate was set to $0.5 \mathrm{~mL} / \mathrm{min}$, and the OSI signal was detected at $308 \mathrm{~nm}$. The chromatographic apparatus consisted of a Model 1525 pump (Waters Corporation, Milford, MA, USA), a Model 717 Plus auto-injector (Waters Corporation), and a Model 2487 dual-wavelength UV/vis detector (Waters Corporation).

The release kinetics were presented in the form of a ratio of drug released/drug added to dialysis bags against time. The kinetics of OSI release from liposomes was determined using DDSolver software by fitting obtained results to different kinetic models: Higuchi, Krosmeyer-Peppas, Peppas-Sahlin [34].

\subsubsection{Cell Culture}

Human fibroblasts derived from lungs (MRC-5), non-small-cell lung carcinoma cell lines with wild-type EGFR gene (A549), with a deletion in exon 19 of the EGFR gene (PC-9) and bearing mutant EGFR genes T790M and L858R (H-1975), cell culture media, fetal bovine serum (FBS) and penicillin/streptomycin (P/S) were purchased from the American Type Culture Collection (Manassas, VA, USA). Cells were maintained according to a protocol in the medium supplemented with $10 \%$ FBS 
and 1\% P/S: H-1975, PC-9 in Roswell Park Memorial Institute (RPMI) 1640 medium, MRC-5 in Eagle's Minimum Essential Medium (EMEM), A549 in Kaighn's Modification of Ham's F-12 Medium (F-12K).

\subsubsection{In Vitro Cellular Cytotoxicity}

Cells were seeded onto 96 -well plates at a density $5 \times 10^{3}$ cells/well in the culture medium, and allowed to adhere for $24 \mathrm{~h}$ at $37^{\circ} \mathrm{C}$. A stock solution of non-loaded drug in dimethyl sulfoxide (DMSO) and liposomal formulations were diluted using cell culture media up to a final drug concentration ranging from $0.001-5 \mu \mathrm{M}$. Cells were then treated with serially diluted OSI, OSI liposomal formulations and non-loaded liposomes for $72 \mathrm{~h}$. Non-treated cells served as a control. Cell viability was assessed by MTT assay. Briefly, $100 \mu \mathrm{L}$ of MTT in cell culture medium $(1 \mathrm{mg} / \mathrm{mL})$ was added to each well and incubated for $3 \mathrm{~h}$. Subsequently, the medium was removed, and formazan crystals were dissolved with DMSO. The absorbance was measured as a difference between absorbance measured at a measurement wavelength of $570 \mathrm{~nm}$ and a reference wavelength of $650 \mathrm{~nm}$ in an Infinite ${ }^{\circledR}$ NanoQuant M200PRO microplate reader (Tecan Group Ltd., Männedorf, Switzerland). Cell viability was determined as a percentage of control cells. A normalized dose-response inhibition curve fitting was performed in GraphPad Prism 8 (GraphPad Software, San Diego, CA, USA), and subsequently, $\mathrm{IC}_{50}$ values were calculated.

\subsubsection{Cellular Uptake and Localization of Liposomes}

Aliquots of fluorescently-labeled liposomes were prepared for each type of studied formulation according to a procedure described above and presented in Table 1. Phospholipid membrane was stained by the addition of $0.2 \mathrm{~mol} \%$ ammonium salt 1,2-dioleoyl-sn-glycero3-phosphoethanolamine-N-(lissamine rhodamine B sulfonyl) with red fluorescence, (Avanti Polar Lipids). Oregon Green ${ }^{\circledR} 488$ paclitaxel (Thermo Fisher Scientific, Waltham, MA, USA) with green fluorescence was used as a model drug at a final concentration of $1 \mu \mathrm{M}$, following the manufacturer protocol. Prior to the visualization by confocal microscopy, MRC-5 and H-1975 cells were plated (10,000 cells/well) in Nunc ${ }^{\mathrm{TM}}$ Lab-Tek $^{\mathrm{TM}}$ II Chambered Coverglass with a No. 1.5 borosilicate glass bottom, 4-well format plates (Thermo Scientific ${ }^{\mathrm{TM}}$ ), and incubated for $24 \mathrm{~h}$ at $37^{\circ} \mathrm{C}$. Fluorescently-labeled formulations were added, and cells were incubated for another hour. Subsequently, the medium was removed, cells were washed twice with PBS and incubated again for 20 min with $5 \mu \mathrm{M}$ nuclear dye 4',6-diamidino-2-phenylindole (DAPI, Thermo Fisher Scientific). Cellular internalization of fluorescently-labeled OSI liposomes was analyzed by a confocal microscope (Leica TCS SP8, Leica Microsystems, Wetzlar, Germany).

\subsubsection{Statistical Analysis}

Statistical analyses were performed with one-way analysis of variance ANOVA followed by Dunnett's multiple comparison test using GraphPad Prism version 8.0 for Windows. The results were presented as the mean \pm SD from three or two independent experiments; $p$ values lower than 0.05 were considered statistically significant.

\section{Results and Discussion}

The ultimate goal of the presented study was the development of a liposome-based carrier capable of delivering a novel TKI, osimertinib. TKIs comprise a large group of therapeutic compounds that have revolutionized anticancer therapy, leading to personalized treatment based on molecular profiling [4,5].

The high cargo capacity and the existence of several clinically approved products make nanoparticulate liposomal vesicles ideal candidates for TKIs delivery [19,21,35,36]. The development of optimal liposome-based formulations requires evaluation of a range of parameters that determine performance in vivo, including size, charge, membrane fluidity, particle surface characteristics, and drug loading. It has been shown in numerous preformulation studies that the degree of drug loading, liposomes size, pharmacokinetic properties depends on nature (i.e., physicochemical properties) of 
drugs and the composition of the liposomes (lipids, lipid/cholesterol ratio, drug/lipid ratio, and charge of the liposomes), as well as the method used for preparation [37].

\subsection{Preparation Method and Composition}

TKIs are mostly hydrophobic, weakly basic molecules. These properties make TKI potential candidates to be carried by liposomes. TKI can be loaded both in the membrane bilayer via passive loading and in the internal aqueous core by applying active loading; both strategies have yielded clinically useful formulations of other drugs and also have been widely explored to prepare liposomal formulations of other TKIs $[17,18,21,38]$. Here, we examined and compared the properties of liposomes loaded with OSI (a new TKI applied in NSCLC) either by a passive or active method. Characteristics of 12 types of liposomes used in this study, which differ from each other in lipid composition and method used for drug loading is presented in Table 1.

With the passive loading method, the drug is loaded during liposome formation and is incorporated within the lipid membrane.

In contrast, with the active loading triggered by ammonium sulfate gradient, a drug is loaded after liposome formation. The resulting OSI-loaded formulations can be distinguished simply by visual observations. As presented in Figure 1, samples loaded with OSI by passive loading are opalescent (1-OSI, 2-OSI, 3-OSI) because the drug is incorporated (solubilized) in the lipid matrix. Samples loaded by ammonium sulfate gradient are yellow (4-OSI, 5-OSI, 6-OSI), due to OSI precipitated in the liposomal aqueous core. Similarly, the market-approved liposomal product of doxorubicin was prepared by a transmembrane ammonium sulfate gradient with doxorubicin precipitated as a sulfate salt inside vesicles [39,40].

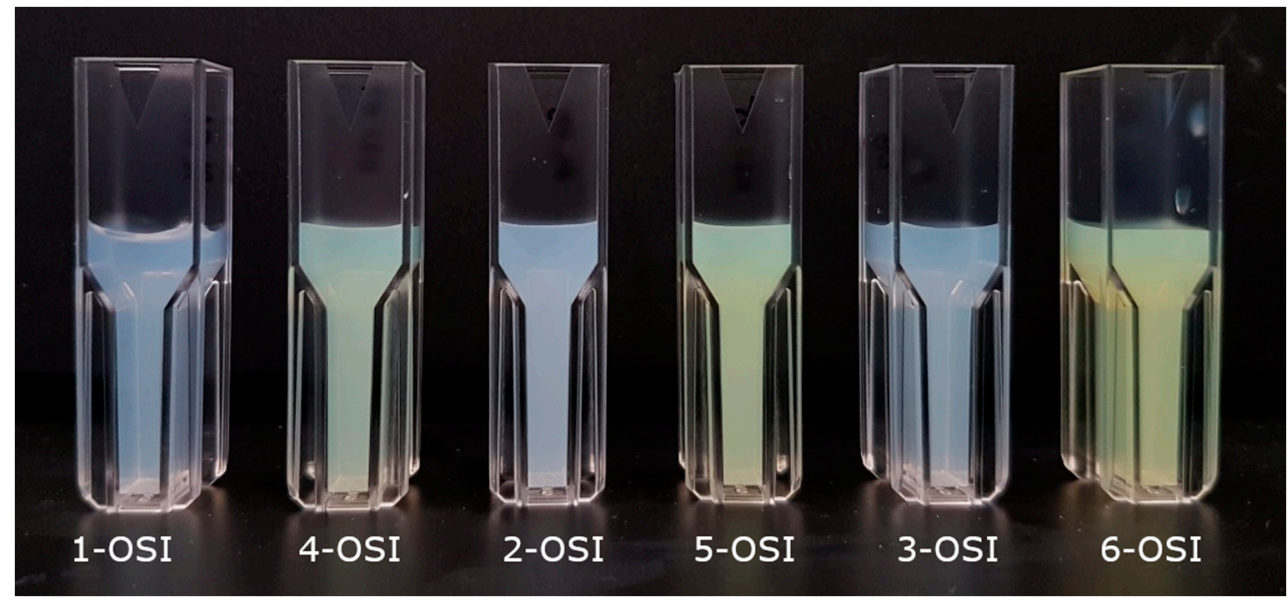

Figure 1. Appearance of liposomal solutions in PBS, pH 7.4 containing liposomes loaded with osimertinib (OSI), is dependent on the drug loading method. Samples loaded with OSI by passive loading are opalescent (1-OSI, 2-OSI, 3-OSI), because the drug is incorporated (solubilized) in the lipid matrix. Samples loaded by ammonium sulfate gradient are yellow (4-OSI, 5-OSI, 6-OSI), which is caused by OSI precipitated in the liposomal aqueous core.

In this study, to prepare OSI-liposomes, we used phospholipids and lipid molecules (cholesterol) that have been widely used to formulate liposome-based drug delivery systems, including those clinically approved.

\subsection{Encapsulation Efficacy}

The passive loading is an equilibrium process dependent on parameters, such as the internal and external liposomal volume ratio, drug concentration and solubility in the hydration medium, amount of lipids used to prepare vesicles. The encapsulation efficacy is usually lower compared to remote/active 
loading [41]. OSI is encapsulated at higher loads, nearly 100\% when prepared via active loading, irrespectively of PC type used (Figure 2A). Encapsulation efficacy varies among samples prepared by thin lipid hydration accompanied by passive loading of the drug with the use of different PC types. Figure 2A demonstrates that the highest loading efficacy, in case of samples loaded passively, was observed for liposomes composed of an egg-PC of natural origin, which is unsaturated, asymmetric phospholipid. EE was decreased for saturated, symmetrical DPPC (C16) and further for a long chain (C18), DSPC. Encapsulation efficacy can be affected by many factors involving the preparation method, a type of phospholipid used. Here, we have observed that the loading decreased with an increase in phase transition temperature of the $\mathrm{PC}$, forming the liposomal membrane. Our results are in agreement with research presented by Trummer et al. [17] regarding the loading of gefitinib into liposomal vesicles. Briefly, in the study, they described poor gefitinib incorporation into liposomes when solid, high phase transition lipids such as DSPC where used on the contrary to the more fluid vesicles [17].

A

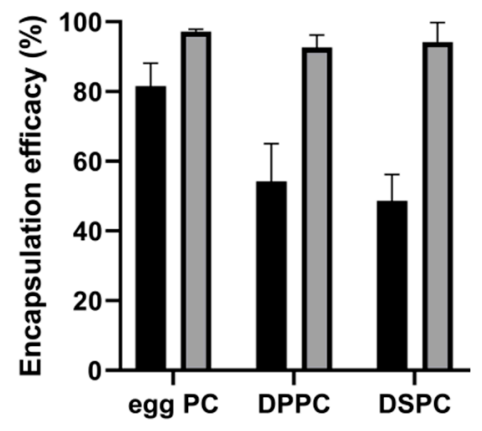

B

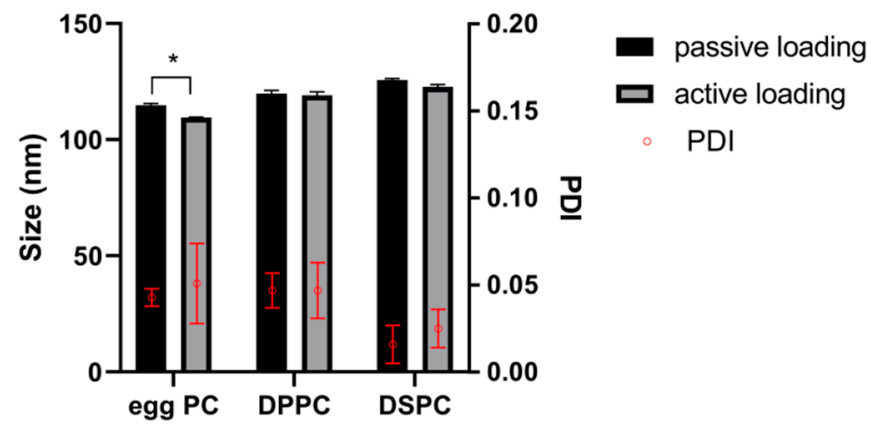

Figure 2. (A) -Encapsulation efficacy (\%) of osimertinib (OSI) into liposomes composed of different phospholipids (egg-PC, DPPC, DSPC), via passive and active loading method; (B)—size and polydispersity index (PDI) of OSI-loaded liposomes. Means \pm SD are shown. ${ }^{*} p<0.05$.

\subsection{Liposomes Size}

Liposome size and size distribution are critical attributes of the nanoparticulate formulation. Liposome size contributes to the passive tumor-targeting of nanoparticles via enhanced permeation and retention (EPR) [42]. Therefore the vast majority of liposome-based systems, being used as drug delivery agents, involving clinically approved products, have particles of 80-130 nm. For example, vesicles of liposomal doxorubicin (Doxil ${ }^{\circledR}$ ) have diameters in the range $80-100 \mathrm{~nm}$, liposomal vincristine (Marqibo ${ }^{\circledR}$ ) $-100 \mathrm{~nm}$, while nanoparticle albumin-bound paclitaxel (Abraxane ${ }^{\circledR}$ ) has particles size of $130 \mathrm{~nm}[38,43,44]$. Dynamic light scattering studies revealed that tested OSI-loaded liposomes had diameters in the range of 109.6-125.7 nm (Figure 2B). Egg-PC-based formulations seemed smaller than those prepared with DPPC or DSPC. These results were statistically significant for samples prepared by active loading, and for egg-PC and DSPC formulations obtained by passive loading. We did not observe any profound influence of the drug loading method on the liposome size. Statistically significant differences $(p<0.05)$ were found only in the case of formulations containing egg-PC and the liposomes prepared by passive loading had a bigger size $(114.8 \pm 0.8 \mathrm{~nm})$ than the actively loaded ones $(109.6 \pm 0.1 \mathrm{~nm})$.

The polydispersity index (PDI) for all studied formulations was below 0.1, pointing out homogenous and monomodal size distribution. The values of PDI of DSPC-based liposomal samples were lower than egg-PC- and DPPC-based formulations. However, the differences were not statistically significant. 


\subsection{Stability}

Liposomes represent the example of colloidal systems; therefore, in certain circumstances, the particles in a liposomal dispersion may adhere to one another and form aggregates of successively increasing size, which may settle out under the influence of gravity. The liposomal surface was modified with PEG by incorporating into the liposomal membrane a modified phospholipid, PEG2000-DSPE ( $5 \mathrm{~mol} \%)$, to enhance steric stability of developed liposomes and reduce its uptake by cells of the reticuloendothelial system.

Physical stability of the liposomal dispersion is usually monitored by controlling the size of the particles over the storage time in the medium of choice (buffer or albumin containing buffer solution). In the presented study, a 90-day physical stability test of the OSI-loaded liposomes stored at $4{ }^{\circ} \mathrm{C}$ in 10 mM PBS (pH 7.4) was conducted. DLS measurements were performed on day 0, 60, 90, following preparation (Figure 3), and no statistical differences were found in the particle size over time.

A

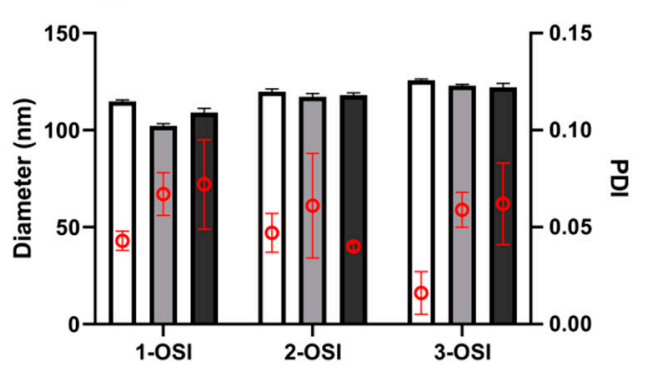

B

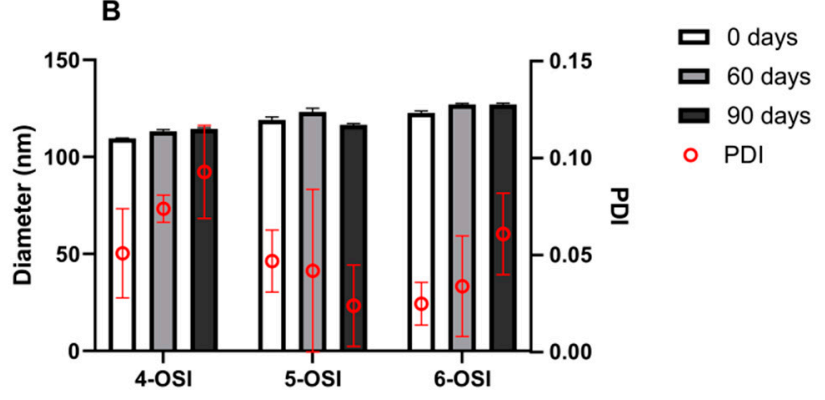

Figure 3. Particle size and PDI stability of OSI-loaded liposomes prepared by passive loading (A) or active loading (B), during 3-month storage in PBS, $\mathrm{pH} 7.4$ at $4{ }^{\circ} \mathrm{C}$. DLS measurements were performed on day $0,60,90$ following preparation $(n=3)$. Means \pm SD are shown.

Zeta potential is a standard analytical measurement for nanoparticle surface characterization. It is a parameter often used to monitor the stability of colloidal dispersion. The zeta potential of 'naked' liposomes (with no PEG present on the liposome surface) was ca. $-40 \mathrm{mV}$ (data not shown). The zeta potential of the studied OSI-liposomes (1-OSI-6-OSI) and drug-free liposomes (1-NL-6-NL) was measured by DLS. The determined values were in the range of $-10.2--11.9 \mathrm{mV}$. These data correspond to the zeta potential reported for liposomes containing similar content (2-5 mol\%) of PEG derivatized phospholipid previously reported $[45,46]$. The data also agree with the finding that the PEG chains covering the liposome surface reduce the absolute value of zeta potential $[45,46]$. The zeta potential was shown to get lower with increasing concentration of PEGylated phospholipid and eventually reached a plateau around $-5 \mathrm{mV}$ [46]. That decrease in the absolute value of zeta potential can be attributed to the following mechanisms: (i) the slipping plane being moved further away from the liposome surface and (ii) the drag caused by the presence of the PEG chains on the liposome surface reducing the mobility of the liposomes (and hence the zeta potential) [46].

\subsection{In Vitro Drug Release}

The mechanism of drug release from liposomes is based on passive drug permeation and diffusion. Drug release from liposomal carriers is a complex process affected by the physicochemical properties of the liposome and the physical state of the encapsulated drug, as well as external factors such as the release medium selection, temperature and $\mathrm{pH}$. The physicochemical properties that determine drug release from liposomes include drug permeability, drug ionization constant, drug binding behavior with the lipid bilayer, self-association of the drug, and the presence of intraliposomal precipitate [47].

The OSI release from liposomes was studied in vitro by a dialysis method. The effect of preparation method and vesicle composition on the release profile was evaluated. The influence of neutral (7.4) and acidic (6.1) $\mathrm{pH}$ on OSI release from liposomes was also studied regarding different $\mathrm{pH}$ conditions 
in the extracellular environment of normal and cancer cells. Acidification of the extracellular milieu and concomitant intracellular alkalization of the cytoplasm are well-known hallmarks of cancer [48,49], which may affect the release profile of the drug, mostly weak acids and bases.

The experimental release profiles, presented in Figure 4, show that OSI, being located within different liposomal compartments and in a different molecular form, behaves differently. As mentioned in the paragraph Preparation method and composition, OSI loaded passively is incorporated into the lipid membrane. In that compartment of the liposome, OSI is present in the non-ionized form, which was quickly released from the vesicles when PBS at both $\mathrm{pH}$ values was used (Figure 4A). In the case of gradient-loaded liposomes, OSI was encapsulated in the form of precipitated salt (sulfate). Despite the different $\mathrm{pH}$ conditions applied, a standard release-testing method using phosphate-buffered saline is not sufficient (see Figure 4B), because the drug release is not dominated by simple diffusion but by a gradient-related diffusion [50,51].

A

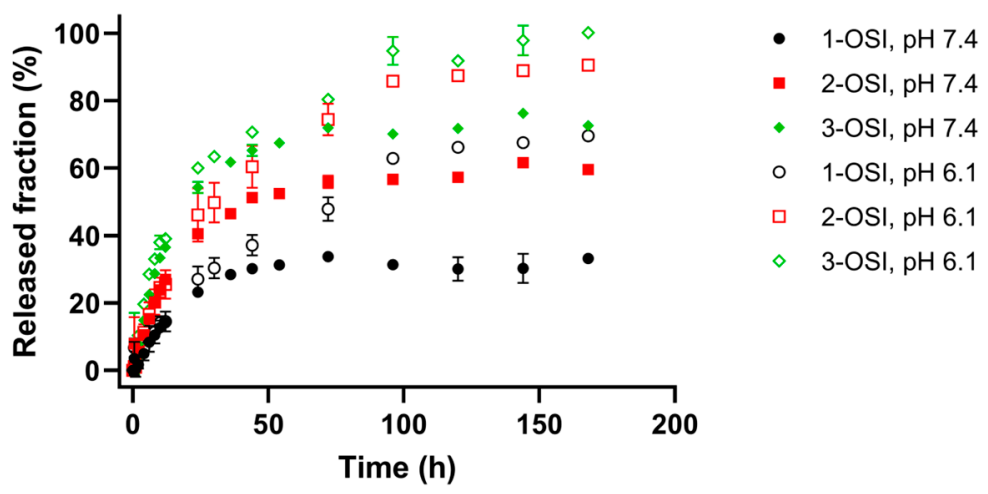

B

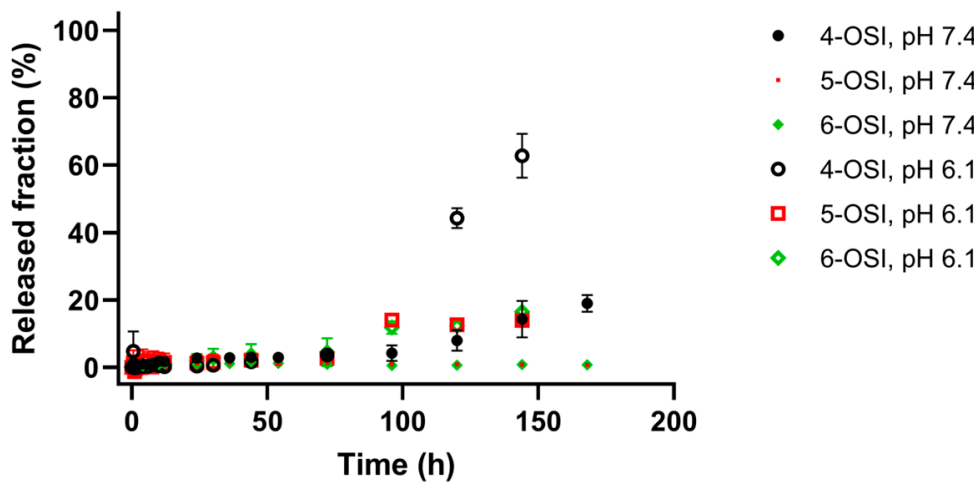

Figure 4. Cumulative release profiles of osimertinib (OSI) from liposomes composed of egg-PC (black circles), DPPC (red squares), DSPC (green diamonds) prepared by passive loading (A) or active loading (B). $10 \mathrm{mM}$ PBS was used as a release medium with $\mathrm{pH}$ adjusted to neutral (7.4) or acidic (6.1). Means $\pm \mathrm{SD}$ are shown.

The time $\left(\mathrm{T}_{50}\right)$ at which approximately $50 \%$ of OSI was released from passively-loaded liposomes was estimated and shown in Table 2. It can be noted that $\mathrm{T}_{50}$ decreased when the PBS buffer at $\mathrm{pH} 6.1$ was used as a release medium. This can be explained by increased solubility of OSI (a weak base) in an acidic environment, which enabled quicker diffusion of drug molecules. Furthermore, the release profiles in Figure 4A, showed that an increase in drug release rate is not only $\mathrm{pH}$-dependent but also depends on the character of the dominant phospholipid. 
Table 2. Parameters obtained by fitting the in vitro release data of OSI from liposomal formulations to three mathematical models.

\begin{tabular}{|c|c|c|c|c|c|c|c|}
\hline \multirow{3}{*}{ Model } & \multirow{3}{*}{ Parameter } & \multicolumn{6}{|c|}{ Formulation } \\
\hline & & 1-OSI & 2-OSI & 3-OSI & 1-OSI & 2-OSI & 3-OSI \\
\hline & & \multicolumn{3}{|c|}{ pH 7.4} & \multicolumn{3}{|c|}{ pH 6.1} \\
\hline \multicolumn{8}{|c|}{ Higuchi; $\frac{M_{t}}{M_{\infty}}=k_{H} t^{1 / 2}$} \\
\hline & $k_{H}$ & 3.365 & 5.816 & 10.179 & 5.595 & 8.141 & 11.423 \\
\hline & $R^{2}$ & 0.805 & 0.882 & 0.963 & 0.955 & 0.942 & 0.953 \\
\hline & AIC & 116.350 & 126.699 & 57.458 & 71.072 & 61.275 & 53.025 \\
\hline & $\mathrm{T}_{50}(\mathrm{~h})$ & 220.772 & 73.910 & 24.130 & 79.865 & 37.723 & 19.161 \\
\hline \multicolumn{8}{|c|}{ Korsmeyer-Peppas; $\frac{M_{t}}{M_{\infty}}=k_{K P} t^{n}$} \\
\hline & $k_{K P}$ & 6.767 & 10.490 & 7.805 & 2.921 & 5.126 & 8.030 \\
\hline & $n$ & 0.342 & 0.367 & 0.593 & 0.665 & 0.650 & 0.644 \\
\hline & $R^{2}$ & 0.886 & 0.935 & 0.978 & 0.990 & 0.980 & 0.982 \\
\hline & AIC & 108.714 & 117.946 & 53.791 & 53.748 & 51.578 & 45.218 \\
\hline & $\mathrm{T}_{50}(\mathrm{~h})$ & 346.892 & 70.771 & 22.899 & 71.364 & 33.181 & 17.129 \\
\hline \multicolumn{8}{|c|}{ Peppas-Sahlin; $\frac{M_{t}}{M_{\infty}}=k_{1} t^{m}+k_{2} t^{2 m}$} \\
\hline & $k_{1}$ & 3.664 & 6.200 & 5.244 & 2.313 & -21.099 & -33.843 \\
\hline & $k_{2}$ & -0.095 & -0.157 & -0.111 & 1.209 & 22.926 & 38.891 \\
\hline & $m$ & 0.641 & 0.624 & 0.865 & 0.401 & 0.200 & 0.176 \\
\hline & $R^{2}$ & 0.974 & 0.985 & 0.989 & 0.988 & 0.990 & 0.994 \\
\hline & AIC & 82.091 & 91.581 & 45.395 & 55.059 & 42.983 & 33.540 \\
\hline & $\mathrm{T}_{50}(\mathrm{~h})$ & None Calc & 48.988 & 19.872 & 71.670 & 32.513 & 17.074 \\
\hline
\end{tabular}

$M_{\infty}$ is the amount of drug at the equilibrium state (sometimes very close to the amount of drug contained in the dosage form at the beginning of the release process); $M_{t}$ is the amount of drug released over time $t ; k_{H}, k_{K P}$, $k_{1}, k_{2}$-are the release constant of Higuchi, Korsmeyer-Peppas and Peppas-Sahlin, and are constants of incorporation of structural modifications and geometrical characteristics of the system; $n, m$ is the exponent of release, related to the drug release mechanism in function of time $t ; R$-correlation coefficient; AIC-Akaike information criterion; $\mathrm{T}_{50}$-time at which $50 \%$ of a drug is released [52].

The highest release rate was observed for DSPC, which simultaneously is characterized by the highest $\mathrm{T}_{\mathrm{m}}$. Due to the lower transition temperature of egg-PC $\left(25^{\circ} \mathrm{C}\right)$ in comparison to DPPC (49 $\left.{ }^{\circ} \mathrm{C}\right)$ and DSPC $\left(55^{\circ} \mathrm{C}\right)$, egg-PC/cholesterol liposomes are more fluid than the DPPC/cholesterol or DSPC/cholesterol liposomes at $37^{\circ} \mathrm{C}$ [39]. Usually, more fluid liposomal formulations are more "leaky" and release an incorporated drug at a higher rate. In the presented study, however, the drug release rate increased when the saturated phospholipids were used (egg-PC vs. DPPC) and with the length of the lipid carbon chains (DPPC vs. DSPC). Both higher OSI encapsulation efficacy and slower release rate from egg-PC/cholesterol-based liposomes may point out that there some nonpolar regions ("pockets") of the membrane which interact with OSI stronger than those formed in the liposome membrane based on DPPC or DSPC.

\subsection{Mathematical Modeling of OSI Release from Liposomes}

To better understand the release mechanism underlying OSI release from evaluated formulations, data were fitted to the following mathematical models: Higuchi, Peppas-Sahlin, Korsmeyer-Peppas, using DDSolver software [34].

Mathematical models are an essential tool to design pharmaceutical formulations, evaluate drug release processes in vitro and in vivo and, in general, come up with the optimal design for new systems [53]. In general, when a hydrophilic drug is incorporated in a matrix, the release occurs easily by diffusion, compared to a hydrophobic or less water-soluble drug. The hydrophobic drug release is typically associated with swelling and/or matrix erosion. The mechanism by which the drug release is governed can be determined by statistical analysis of the first $60 \%$ of all release curves and is based on 
the higher $R^{2}$ and lower Akaike information criterion (AIC) [52]. As shown in Table 2, $R^{2}$ is the highest while AIC is the lowest for the Peppas-Sahlin model in almost all samples, apart from 1-OSI at $\mathrm{pH}=6.1$. The Peppas-Sahlin model is a release kinetics model that assumes two contribution mechanisms, diffusional and relaxational, in an anomalous drug release process. According to Korsmeyer-Peppas release exponent value $n$, and Peppas-Sahlin contribution coefficient $m$, drug dissolution in combination with diffusion and liposome relaxation is considered as the mechanisms for OSI release from the liposomal matrix.

\subsection{Cellular Uptake and Localization of Liposomes}

In order to show that liposomes with incorporated drug can penetrate into cellular cytoplasm and release the payload, we labeled liposomes (1-OSI formulation) with rhodamine (red fluorescence) and used commercially available paclitaxel labeled with Oregon Green (green fluorescence) and incubated with human H-1975 EGRF mutation-positive non-small lung cancer cells and MRC-5 diploid human cell culture line composed of fibroblasts derived from lungs. In addition, cell nuclei were stained with DAPI nuclear dye (blue fluorescence). It is known that liposomes are quenching fluorescence of compounds incorporated into liposomes [54]. Thus, the fluorescence of labeled drug (paclitaxel) is quenched inside the liposomes. Therefore, a presence of green fluorescence inside the cellular cytoplasm documents the release of the drug from the liposomes and its intracellular localization. It can be seen that liposomes with the drug penetrated cancerous and normal lung cells, localized predominately in the cytoplasm and release the drug into the cytoplasm. The representative images shown in Figures 5 and 6 demonstrate that liposomes are successfully internalized into the both investigated cells and released the drug.
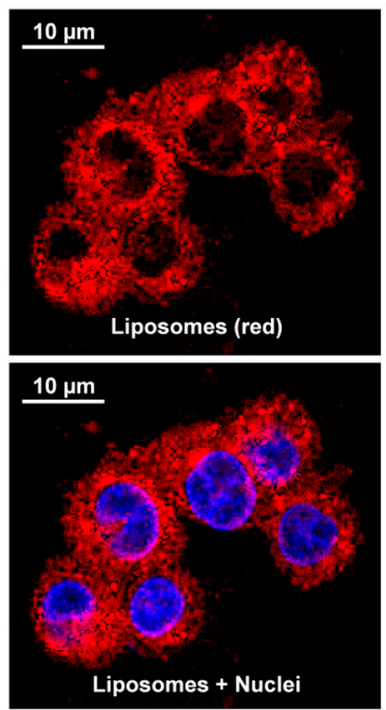
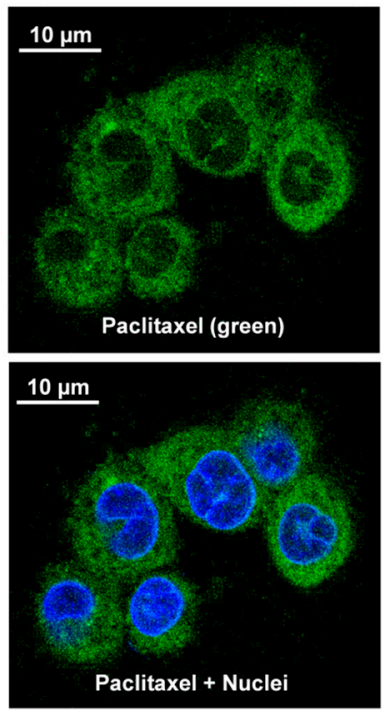
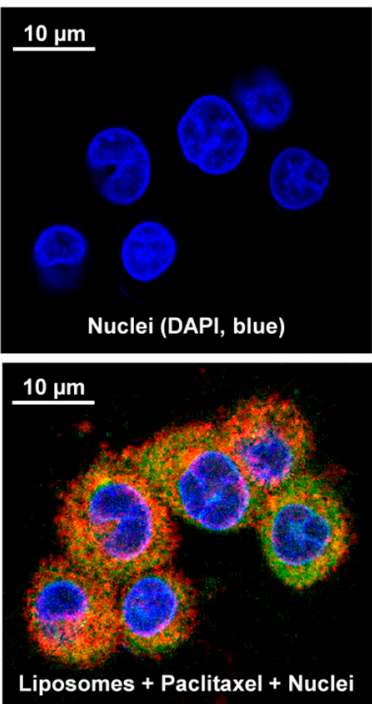

Figure 5. Cellular Internalization of Liposomes (Red Fluorescence) Containing Paclitaxel (Green Fluorescence) by Confocal Microscope (Leica TCS SP8, Leica Microsystems, Wetzlar, Germany). Human H1975 non-small lung cancer cells were incubated with liposomes (Rhodamine, red fluorescence) containing paclitaxel (Oregon Green, green fluorescence). Nuclei were stained with DAPI (blue fluorescence). Superimposition of red and green colors gives yellow color. Representative images are shown. 

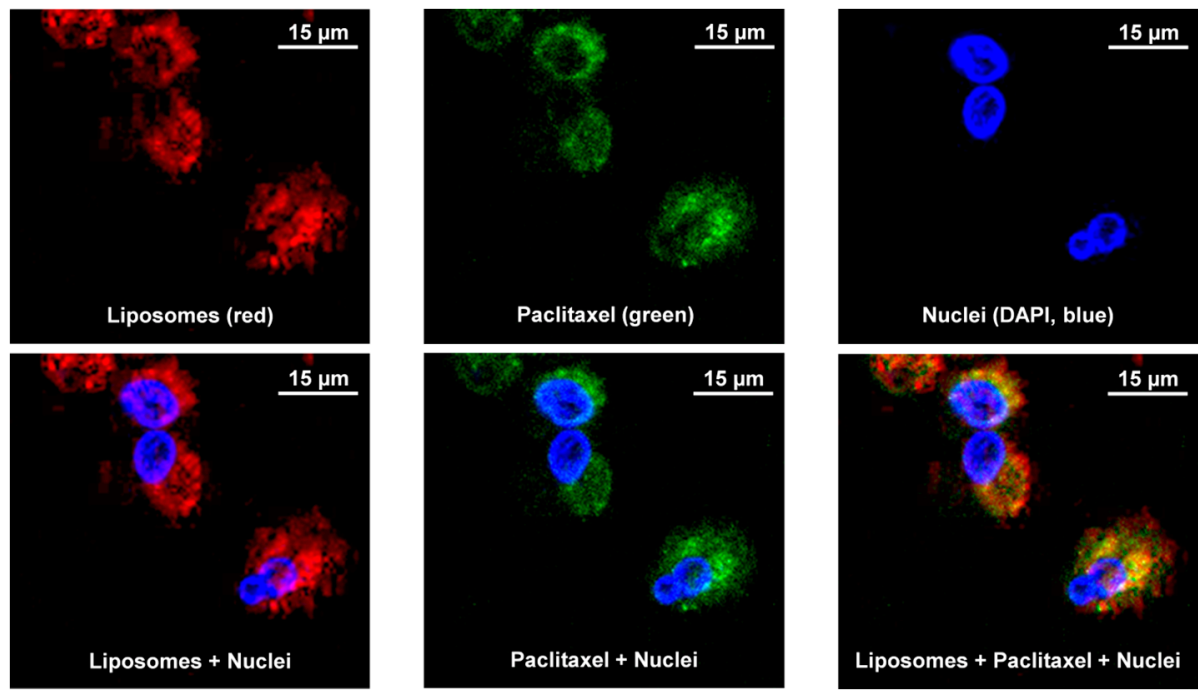

Figure 6. Cellular Internalization of Liposomes (Red Fluorescence) Containing Paclitaxel (Green Fluorescence) by Confocal Microscope (Leica TCS SP8, Leica Microsystems, Wetzlar, Germany). Human MRC-5 normal lung cells were incubated with liposomes (Rhodamine, red fluorescence) containing paclitaxel (Oregon Green, green fluorescence). Nuclei were stained with DAPI (blue fluorescence). Superimposition of red and green colors gives yellow color. Representative images are shown.

Generally, liposome particles are taken up by endocytotic processes and eventually reach the lysosome [55,56]. In the lysosome, liposomes and their encapsulated cargo are exposed to acidic conditions and the risk of being degraded by lysosomal enzymes [57]. For example, liposomal doxorubicin Doxil ${ }^{\circledR}$, was shown to utilize caveolae-mediated endocytosis to internalize into epithelial cancer cells in a study by Sahay et al. [58]. Following internalization, DOXIL ${ }^{\circledR}$ nanoparticles accumulated in lysosomes, where the doxorubicin was released [58]. Based on the above reports and the known pathway of liposome internalization via endocytosis, it can be assumed that liposomes reach lysosomes where acidic $\mathrm{pH}$ conditions and enzymatic degradation of the carrier enables drug release and support solubilization (due to protonation) of OSI molecules. As we noticed in the in vitro release study, the OSI release rate, well seen in case of passively loaded liposomes, increases with the decrease of $\mathrm{pH}$. Furthermore, we may also assume that the degradation of liposomes in the lysosomal compartment may trigger and accelerate the release of OSI from actively loaded liposomes.

\subsection{Cytotoxicity}

The cytotoxic activity of liposomal OSI was evaluated in vitro across MRC-5 cells, which are human fibroblasts derived from lungs and H-1975 cells, which is non-small-cell lung carcinoma cell line bearing mutant EGFR gene (T790M and L858R). For these studies, the incubation time of the formulation with the cells was $72 \mathrm{~h}$ with OSI at a concentration of $0.0001-5 \mu \mathrm{M}$, based on previous literature reports $[59,60]$.

In H-1975 cells, all liposomal formulations of OSI exhibited lower IC $_{50}(4.57-6.21 \mathrm{nM})$ compared to free OSI $(8.08 \mathrm{nM})$ in MTT assay (Figure 7$)$. However, the $\mathrm{IC}_{50}$ of only 1-OSI was significantly lower in comparison to the non-incorporated drug $(p<0.05)$. As shown in Figure 7, MRC- 5 cells, which do not overexpress EGFR, do not respond to OSI treatment, either a free drug or liposomal form, at concentrations lower than $1 \mu \mathrm{M}$. An MTT assay was conducted on liposomes without drug incorporated, by using the same dilutions of non-loaded liposomes as used for OSI-loaded samples to examine the possible bioactivity of non-loaded liposomes themselves against H-1975 and MRC-5. The results show that 1-NL-6-NL liposomes only demonstrated a minor impact on the proliferation of the H-1975 and MRC-5 cells at extremely high lipid concentration with co-incubation times as long as $72 \mathrm{~h}$. 

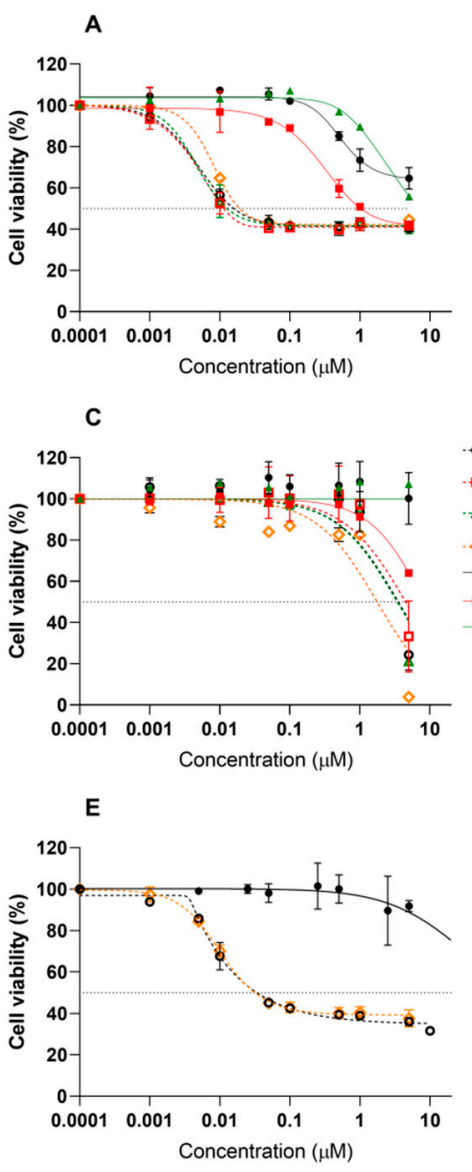

B
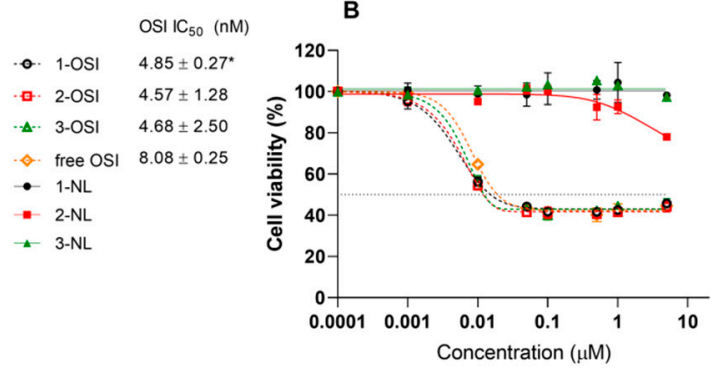

OSI IC $50(\mathrm{nM})$

- 4 -OSI $4.94 \pm 1.33$

-7. 5 -OSI $5.47+1.62$

- 6-OSI $6.21 \pm 2.91$

๑. free OSI $8.08 \pm 0.25$

- 4-NL

- $5-\mathrm{NL}$

- 6-NL

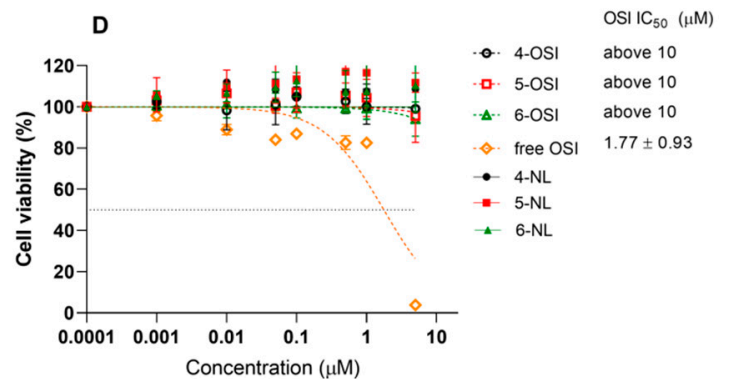

a. 1-OSI $3.56 \pm 1.68$

ㅁ. 2-OSI $4.51 \pm 1.95$

A. 3 -OSI $3.43 \pm 1.71$

6. free OSI $1.77 \pm 0.93$

- 1-NL

- $2-\mathrm{NL}$

- $-\mathrm{NL}$

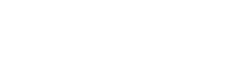

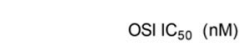

-a. 1 -OSI $10.26 \pm 4.76$

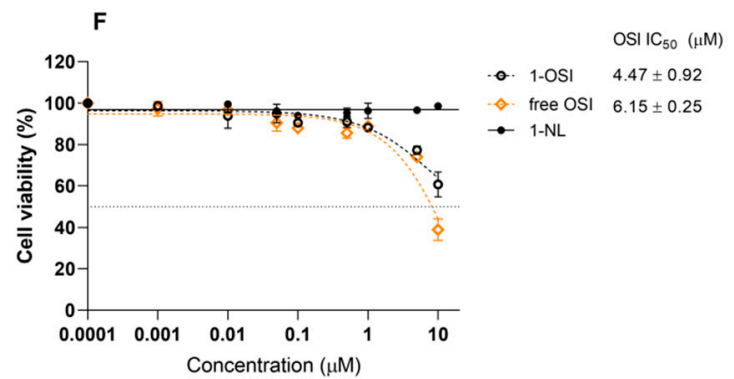

Figure 7. In vitro cytotoxicity and $\mathrm{IC}_{50}$ of free OSI, liposomes loaded with OSI passively (1-, 2-, 3-OSI-(A,C,E,F)) and actively (4-, 5-, 6-OSI-(B,D)) in H-1975 (A,B), MRC-5 cells (C,D), PC-9 (E), A549 (F). To examine the possible cytotoxicity of non-loaded (NL) liposomes, for the cytotoxicity experiments, empty liposomes 1-NL-6-NL were diluted by the same dilution factor as corresponding OSI-loaded formulations. For each group $n=2$ or $n=3$. Means \pm SD are shown. ${ }^{*} p<0.05$ when compared to free non-incorporated drug.

Considering the physicochemical properties and biological activity, we have found egg-PC liposomes as the most promising formulation for further development. Therefore, we additionally tested the cytotoxicity of 1-OSI, 1-NL formulations, and free OSI in other NSCLC, PC-9 cell line with a deletion in exon 19 of the EGFR gene which is sensitive to OSI [61], and A549 line with wild type EGFR gene which is known to be resistant to OSI treatment [62]. As shown in Figure 7E,F, cytotoxicity profiles determined for OSI and its liposomal form $\left(\mathrm{IC}_{50}\right.$ at ca. $\left.10 \mathrm{nM}\right)$ in PC-9 cells are similar to those plotted for the same formulations in H-1975 (Figure 7A). Egg-PC-based liposomal OSI below $5 \mu \mathrm{M}$ did not affect the viability of A549.

\section{Conclusions}

In the study, we proposed a liposome-based delivery system for novel TKI, osimertinib, which is used for the personalized treatment of NSCLC with EGFR mutations. We showed that OSI could be loaded into liposomes passively by hydration method or actively by gradient-loading technique. The above methods led to OSI incorporation in the liposomal membrane and in the aqueous core, respectively. The obtained vesicles did not differ much in terms of size, PDI, zeta potential, and stability. Since drug substance was located in different compartments of the liposome, different entrapment efficacy and OSI release profiles were achieved.

Based on the presented results, mostly encapsulation efficacy, in vitro drug release and cytotoxicity, we identified liposomes composed of egg-PC as the most suitable carrier for OSI that can be considered 
for further development. Above all, OSI loaded into liposomes composed of egg-PC showed higher antitumor efficacy against cancer cells with EGFR mutations than free OSI and did not affect the viability of normal lung fibroblasts. Apart from improved drug performance, the choice of egg-PC, which is a phospholipid of natural origin, can be considered advantageous for further development. Natural phospholipids are more sustainable products derived from abundantly available raw material sources and are preferred compared to synthetic phospholipids [63].

In the future perspective, with a formulation developed, we can continue our studies on liposomal OSI and consider various routes of administration (intravenous, inhalation). All the more important, there is a clinical need for novel EGFR-TKIs with improved efficacy against brain lesions. The ability of OSI to penetrate the blood-brain barrier and the potential usefulness in the treatment of CNS metastases or leptomeningeal disease (related to NSCLC), supported by effective drug carriers and delivery route, may bring this concept to success.

Author Contributions: Conceptualization, P.S.-M. and T.M.; methodology, P.S.-M. and T.M.; validation, P.S.-M.; formal analysis, P.S.-M.; investigation, P.S.-M.; resources, P.S.-M.; data curation, P.S.-M.; writing-original draft preparation, P.S.-M.; writing-review and editing, T.M.; visualization, P.S.-M. and T.M.; supervision, T.M.; project administration, T.M.; funding acquisition, P.S.-M. and T.M. All authors have read and agreed to the published version of the manuscript.

Funding: P.S.-M. received funding provided by the European Union's Horizon 2020 research and innovation program under the Marie Sklodowska-Curie grant agreement No 778051 and the Ministry of Science and Higher Education of Poland fund for supporting internationally co-financed projects in 2018-2022 (agreement No 3899/H2020/2018/2). T.M. acknowledges the financial support provided by the National Institutes of Health (grant numbers: R01 CA238871 and R01 CA209818).

Conflicts of Interest: The authors declare no conflict of interest. This article reflects the authors' view only. Neither the Research Executive Agency nor the Polish Ministry of Science and Higher Education may be held responsible for the use which may be made of the information contained therein.

\section{References}

1. Siegel, R.L.; Miller, K.D.; Jemal, A. Cancer statistics, 2020. CA Cancer J. Clin. 2020, 70, 7-30. [CrossRef] [PubMed]

2. Cancer Statistics-Eurostat. 2020. Available online: https://ec.europa.eu/eurostat/statistics-explained/index. php?title=Cancer_statistics_-_specific_cancers\#Lung_cancer (accessed on 5 May 2020).

3. Zeng, X.; Wan, X.; Xu, J.; Wang, H.; Chen, H.; Zeng, Q.; Zhang, W.; Zhao, B. Therapeutic options for advanced epidermal growth factor receptor (EGFR)-mutant non-small cell lung cancer: A Bayesian network secondary analysis. Aging 2020, 12, 7129. [CrossRef] [PubMed]

4. Halliday, P.R.; Blakely, C.M.; Bivona, T.G. Emerging targeted therapies for the treatment of non-small cell lung cancer. Curr. Oncol. Rep. 2019, 21, 21. [CrossRef] [PubMed]

5. Herbst, R.S.; Morgensztern, D.; Boshoff, C. The biology and management of non-small cell lung cancer. Nature 2018, 553, 446-454. [CrossRef]

6. Yuan, M.; Huang, L.-L.; Chen, J.-H.; Wu, J.; Xu, Q. The emerging treatment landscape of targeted therapy in non-small-cell lung cancer. Signal Transduct. Target. Ther. 2019, 4, 1-14. [CrossRef]

7. Politi, K.; Herbst, R.S. Lung cancer in the era of precision medicine. Clin. Cancer Res. 2015, 21, 2213-2220. [CrossRef]

8. Pao, W.; Chmielecki, J. Rational, biologically based treatment of EGFR-mutant non-small-cell lung cancer. Nat. Rev. Cancer 2010, 10, 760-774. [CrossRef]

9. Maemondo, M.; Inoue, A.; Kobayashi, K.; Sugawara, S.; Oizumi, S.; Isobe, H.; Gemma, A.; Harada, M.; Yoshizawa, H.; Kinoshita, I.; et al. Gefitinib or chemotherapy for non-small-cell lung cancer with mutated EGFR. N. Engl. J. Med. 2010, 362, 2380-2388. [CrossRef]

10. Zhou, C.; Wu, Y.-L.; Chen, G.; Feng, J.; Liu, X.-Q.; Wang, C.; Zhang, S.; Wang, J.; Zhou, S.; Ren, S.; et al. Erlotinib versus chemotherapy as first-line treatment for patients with advanced EGFR mutation-positive non-small-cell lung cancer (OPTIMAL, CTONG-0802): A multicentre, open-label, randomised, phase 3 study. Lancet Oncol. 2011, 12, 735-742. [CrossRef] 
11. Wu, Y.-L.; Zhou, C.; Hu, C.-P.; Feng, J.; Lu, S.; Huang, Y.; Li, W.; Hou, M.; Shi, J.H.; Lee, K.Y.; et al. Afatinib versus cisplatin plus gemcitabine for first-line treatment of Asian patients with advanced non-small-cell lung cancer harbouring EGFR mutations (LUX-Lung 6): An open-label, randomised phase 3 trial. Lancet Oncol. 2014, 15, 213-222. [CrossRef]

12. Yu, H.A.; Arcila, M.E.; Rekhtman, N.; Sima, C.S.; Zakowski, M.F.; Pao, W.; Kris, M.G.; Miller, V.A.; Ladanyi, M.; Riely, G.J. Analysis of tumor specimens at the time of acquired resistance to EGFR TKI therapy in 155 patients with EGFR mutant lung cancers. Clin. Cancer Res. 2013, 19, 2240-2247. [CrossRef] [PubMed]

13. Ramalingam, S.S.; Gray, J.E.; Ohe, Y.; Cho, B.C.; Vansteenkiste, J.; Zhou, C.; Reungwetwattana, T.; Cheng, Y.; Chewaskulyong, B.; Shah, R.; et al. LBA5_PR-Osimertinib vs comparator EGFR-TKI as first-line treatment for EGFRm advanced NSCLC (FLAURA): Final overall survival analysis. Ann. Oncol. 2019, 30, v914-v915. [CrossRef]

14. Soria, J.-C.; Ohe, Y.; Vansteenkiste, J.; Reungwetwattana, T.; Chewaskulyong, B.; Lee, K.H.; Dechaphunkul, A.; Imamura, F.; Nogami, N.; Kurata, T.; et al. Osimertinib in untreated EGFR-mutated advanced non-small-cell lung cancer. N. Engl. J. Med. 2018, 378, 113-125. [CrossRef] [PubMed]

15. Tagrisso. Available online: https://www.ema.europa.eu/en/medicines/human/EPAR/tagrisso (accessed on 5 May 2020).

16. Vrignaud, S.; Hureaux, J.; Wack, S.; Benoit, J.-P.; Saulnier, P. Design, optimization and in vitro evaluation of reverse micelle-loaded lipid nanocarriers containing erlotinib hydrochloride. Int. J. Pharm. 2012, 436, 194-200. [CrossRef]

17. Trummer, B.J.; Iyer, V.; Balu-Iyer, S.V.; O'Connor, R.; Straubinger, R.M. Physicochemical properties of EGF receptor inhibitors and development of a nanoliposomal formulation of gefitinib. J. Pharm. Sci. 2012, 101, 2763-2776. [CrossRef]

18. Zhou, X.; Tao, H.; Shi, K.-H. Development of a nanoliposomal formulation of erlotinib for lung cancer and in vitro/in vivo antitumoral evaluation. Drug Des. Dev. Ther. 2017, 12,1-8. [CrossRef]

19. Xu, H.; He, C.; Liu, Y.; Jiang, J.; Ma, T. Novel therapeutic modalities and drug delivery-erlotinib liposomes modified with galactosylated lipid: In vitro and in vivo investigations. Artif. Cells Nanomed. Biotechnol. 2018, 46, 1902-1907. [CrossRef]

20. Lakkadwala, S.; dos Santos Rodrigues, B.; Sun, C.; Singh, J. Dual functionalized liposomes for efficient co-delivery of anti-cancer chemotherapeutics for the treatment of glioblastoma. J. Control. Release 2019, 307, 247-260. [CrossRef]

21. Lu, X.; Liu, S.; Han, M.; Yang, X.; Sun, K.; Wang, H.; Mu, H.; Du, Y.; Wang, A.; Ni, L.; et al. Afatinib-loaded immunoliposomes functionalized with cetuximab: A novel strategy targeting the epidermal growth factor receptor for treatment of non-small-cell lung cancer. Int. J. Pharm. 2019, 560, 126-135. [CrossRef]

22. Allen, T.M.; Cullis, P.R. Liposomal drug delivery systems: From concept to clinical applications. Adv. Drug Deliv. Rev. 2013, 65, 36-48. [CrossRef]

23. Crommelin, D.J.A.; van Hoogevest, P.; Storm, G. The role of liposomes in clinical nanomedicine development. What now? Now what? J. Control. Release 2020, 318, 256-263. [CrossRef] [PubMed]

24. Kuzmov, A.; Minko, T. Nanotechnology approaches for inhalation treatment of lung diseases. J. Control. Release 2015, 219, 500-518. [CrossRef] [PubMed]

25. Garbuzenko, O.B.; Kuzmov, A.; Taratula, O.; Pine, S.R.; Minko, T. Strategy to enhance lung cancer treatment by five essential elements: Inhalation delivery, nanotechnology, tumor-receptor targeting, chemo- and gene therapy. Theranostics 2019, 9, 8362-8376. [CrossRef] [PubMed]

26. Maeda, H.; Sawa, T.; Konno, T. Mechanism of tumor-targeted delivery of macromolecular drugs, including the EPR effect in solid tumor and clinical overview of the prototype polymeric drug SMANCS. J. Control. Release 2001, 74, 47-61. [CrossRef]

27. Garbuzenko, O.B.; Saad, M.; Pozharov, V.P.; Reuhl, K.R.; Mainelis, G.; Minko, T. Inhibition of lung tumor growth by complex pulmonary delivery of drugs with oligonucleotides as suppressors of cellular resistance. Proc. Natl. Acad. Sci. USA 2010, 107, 10737-10742. [CrossRef]

28. Garbuzenko, O.B.; Mainelis, G.; Taratula, O.; Minko, T. Inhalation treatment of lung cancer: The influence of composition, size and shape of nanocarriers on their lung accumulation and retention. Cancer Biol. Med. 2014, 11, 44-55. [CrossRef]

29. Zang, X.; Lee, J.B.; Deshpande, K.; Garbuzenko, O.B.; Minko, T.; Kagan, L. Prevention of paclitaxel-induced neuropathy by formulation approach. J. Control. Release 2019, 303, 109-116. [CrossRef] 
30. Wu, Y.-L.; Ahn, M.-J.; Garassino, M.C.; Han, J.-Y.; Katakami, N.; Kim, H.R.; Hodge, R.; Kaur, P.; Brown, A.P.; Ghiorghiu, D.; et al. CNS efficacy of osimertinib in patients with T790M-positive advanced non-small-cell lung cancer: Data from a randomized phase III trial (AURA3). J. Clin. Oncol. 2018, 36, 2702-2709. [CrossRef]

31. Vishwanathan, K.; Varrone, A.; Varnas, K.; Jucaite, A.; Cselenyi, Z.; Johnstrom, P.; Schou, M.; Vasquez-Romero, A.; Moein, M.M.; Halldin, C.; et al. Abstract CT013: Osimertinib displays high brain exposure in healthy subjects with intact blood-brain barrier: A microdose positron emission tomography (PET) study with ${ }^{11} \mathrm{C}$-labelled osimertinib. Cancer Res. 2018, 78, CT013. [CrossRef]

32. Lee, J.; Choi, Y.L.; Han, J.; Park, S.; Jung, H.A.; Su, J.-M.; Lee, S.-H.; Ahn, J.S.; Park, K.; Ahn, M.-J. Osimertinib improves overall survival in patients with EGFR-mutated NSCLC with leptomeningeal metastases regardless of T790M mutational status. J. Thorac. Oncol. 2020. [CrossRef]

33. Yang, J.C.H.; Kim, S.-W.; Kim, D.-W.; Lee, J.-S.; Cho, B.C.; Ahn, J.-S.; Lee, D.H.; Kim, T.M.; Goldman, J.W.; Natale, R.B.; et al. Osimertinib in patients with epidermal growth factor receptor mutation-positive non-small-cell lung cancer and leptomeningeal metastases: The BLOOM study. J. Clin. Oncol. 2020, 38, 538-547. [CrossRef] [PubMed]

34. Zhang, Y.; Huo, M.; Zhou, J.; Zou, A.; Li, W.; Yao, C.; Xie, S. DDSolver: An add-in program for modeling and comparison of drug dissolution profiles. AAPS J. 2010, 12, 263-271. [CrossRef] [PubMed]

35. Almurshedi, A.S.; Radwan, M.; Omar, S.; Alaiya, A.A.; Badran, M.M.; Elsaghire, H.; Saleem, I.Y.; Hutcheon, G.A. A novel $\mathrm{pH}$-sensitive liposome to trigger delivery of afatinib to cancer cells: Impact on lung cancer therapy. J. Mol. Liq. 2018, 259, 154-166. [CrossRef]

36. Lei, M.; Ma, G.; Sha, S.; Wang, X.; Feng, H.; Zhu, Y.; Du, X. Dual-functionalized liposome by co-delivery of paclitaxel with sorafenib for synergistic antitumor efficacy and reversion of multidrug resistance. Drug Deliv. 2019, 26, 262-272. [CrossRef]

37. Pattni, B.S.; Chupin, V.V.; Torchilin, V.P. New developments in liposomal drug delivery. Chem. Rev. 2015, 115, 10938-10966. [CrossRef]

38. Gabizon, A.; Martin, F. Polyethylene glycol-coated (pegylated) liposomal doxorubicin. Rationale for use in solid tumours. Drugs 1997, 54 (Suppl. 4), 15-21. [CrossRef]

39. Haran, G.; Cohen, R.; Bar, L.K.; Barenholz, Y. Transmembrane ammonium sulfate gradients in liposomes produce efficient and stable entrapment of amphipathic weak bases. Biochim. Biophys. Acta 1993, 1151, 201-215. [CrossRef]

40. Barenholz, Y. (Chezy) Doxil ${ }^{\circledR}$ _The first FDA-approved nano-drug: Lessons learned. J. Control. Release 2012, 160, 117-134. [CrossRef]

41. Chountoulesi, M.; Naziris, N.; Pippa, N.; Demetzos, C. The significance of drug-to-lipid ratio to the development of optimized liposomal formulation. J. Liposome Res. 2018, 28, 249-258. [CrossRef]

42. Maeda, H.; Wu, J.; Sawa, T.; Matsumura, Y.; Hori, K. Tumor vascular permeability and the EPR effect in macromolecular therapeutics: A review. J. Control. Release 2000, 65, 271-284. [CrossRef]

43. Silverman, J.A.; Deitcher, S.R. Marqibo®(vincristine sulfate liposome injection) improves the pharmacokinetics and pharmacodynamics of vincristine. Cancer Chemother. Pharmacol. 2013, 71, 555-564. [CrossRef] [PubMed]

44. Green, M.R.; Manikhas, G.M.; Orlov, S.; Afanasyev, B.; Makhson, A.M.; Bhar, P.; Hawkins, M.J. Abraxane, a novel Cremophor-free, albumin-bound particle form of paclitaxel for the treatment of advanced non-small-cell lung cancer. Ann. Oncol. 2006, 17, 1263-1268. [CrossRef] [PubMed]

45. Smith, M.C.; Crist, R.M.; Clogston, J.D.; McNeil, S.E. Zeta potential: A case study of cationic, anionic, and neutral liposomes. Anal. Bioanal. Chem. 2017, 409, 5779-5787. [CrossRef] [PubMed]

46. Liposomes and the Use of Zeta Potential Measurements to Study Sterically Stabilized Liposomes. Available online: https://www.azonano.com/article.aspx?ArticleID=1214 (accessed on 12 June 2020).

47. Li, T.; Cipolla, D.; Rades, T.; Boyd, B.J. Drug nanocrystallisation within liposomes. J. Control. Release 2018, 288, 96-110. [CrossRef]

48. Webb, B.A.; Chimenti, M.; Jacobson, M.P.; Barber, D.L. Dysregulated pH: A perfect storm for cancer progression. Nat. Rev. Cancer 2011, 11, 671-677. [CrossRef]

49. Persi, E.; Duran-Frigola, M.; Damaghi, M.; Roush, W.R.; Aloy, P.; Cleveland, J.L.; Gillies, R.J.; Ruppin, E. Systems analysis of intracellular $\mathrm{pH}$ vulnerabilities for cancer therapy. Nat. Commun. 2018, 9, 2997. [CrossRef] 
50. Zhigaltsev, I.V.; Maurer, N.; Akhong, Q.-F.; Leone, R.; Leng, E.; Wang, J.; Semple, S.C.; Cullis, P.R. Liposome-encapsulated vincristine, vinblastine and vinorelbine: A comparative study of drug loading and retention. J. Control. Release 2005, 104, 103-111. [CrossRef]

51. Nakamura, K.; Yoshino, K.; Yamashita, K.; Kasukawa, H. Designing a novel in vitro drug-release-testing method for liposomes prepared by pH-gradient method. Int. J. Pharm. 2012, 430, 381-387. [CrossRef]

52. Bruschi, M.L. 5-Mathematical models of drug release. In Strategies to Modify the Drug Release from Pharmaceutical Systems; Bruschi, M.L., Ed.; Woodhead Publishing: Sawston, UK, 2015; pp. 63-86, ISBN 978-0-08-100092-2.

53. Peppas, N.A.; Narasimhan, B. Mathematical models in drug delivery: How modeling has shaped the way we design new drug delivery systems. J. Control. Release 2014, 190, 75-81. [CrossRef]

54. Torchilin, V.P.; Levchenko, T.S.; Whiteman, K.R.; Yaroslavov, A.A.; Tsatsakis, A.M.; Rizos, A.K.; Michailova, E.V.; Shtilman, M.I. Amphiphilic poly-N-vinylpyrrolidones: Synthesis, properties and liposome surface modification. Biomaterials 2001, 22, 3035-3044. [CrossRef]

55. Liu, X.; Huang, G. Formation strategies, mechanism of intracellular delivery and potential clinical applications of pH-sensitive liposomes. Asian J. Pharm. Sci. 2013, 8, 319-328. [CrossRef]

56. Koshkaryev, A.; Thekkedath, R.; Pagano, C.; Meerovich, I.; Torchilin, V.P. Targeting of lysosomes by liposomes modified with octadecyl-rhodamine B. J. Drug Target. 2011, 19, 606-614. [CrossRef] [PubMed]

57. Sahay, G.; Alakhova, D.Y.; Kabanov, A.V. Endocytosis of nanomedicines. J. Control. Release 2010, 145, $182-195$. [CrossRef] [PubMed]

58. Sahay, G.; Kim, J.O.; Kabanov, A.V.; Bronich, T.K. The exploitation of differential endocytic pathways in normal and tumor cells in the selective targeting of nanoparticulate chemotherapeutic agents. Biomaterials 2010, 31, 923-933. [CrossRef]

59. Wang, N.; Wang, L.; Meng, X.; Wang, J.; Zhu, L.; Liu, C.; Li, S.; Zheng, L.; Yang, Z.; Xing, L.; et al. Osimertinib (AZD9291) increases radio-sensitivity in EGFR T790M non-small cell lung cancer. Oncol. Rep. 2019, 41, 77-86. [CrossRef]

60. Martin, M.J.; Eberlein, C.; Taylor, M.; Ashton, S.; Robinson, D.; Cross, D. Inhibition of oxidative phosphorylation suppresses the development of osimertinib resistance in a preclinical model of EGFR-driven lung adenocarcinoma. Oncotarget 2016, 7, 86313-86325. [CrossRef]

61. Hayakawa, D.; Takahashi, F.; Mitsuishi, Y.; Tajima, K.; Hidayat, M.; Winardi, W.; Ihara, H.; Kanamori, K.; Matsumoto, N.; Asao, T.; et al. Activation of insulin-like growth factor-1 receptor confers acquired resistance to osimertinib in non-small cell lung cancer with EGFR T790M mutation. Thorac. Cancer 2020, 11, 140-149. [CrossRef]

62. Yu, X.; Gao, F.; Li, W.; Zhou, L.; Liu, W.; Li, M. Formononetin inhibits tumor growth by suppression of EGFR-Akt-Mcl-1 axis in non-small cell lung cancer. J. Exp. Clin. Cancer Res. 2020, 39, 62. [CrossRef]

63. van Hoogevest, P. Review-An update on the use of oral phospholipid excipients. Eur. J. Pharm. Sci. 2017, 108, 1-12. [CrossRef]

(C) 2020 by the authors. Licensee MDPI, Basel, Switzerland. This article is an open access article distributed under the terms and conditions of the Creative Commons Attribution (CC BY) license (http://creativecommons.org/licenses/by/4.0/). 